\title{
Anticipation in Schizophrenia: Biology or Bias?
}

Janet E. Johnson, ${ }^{1,2} \dagger$ Jane Cleary, ${ }^{1,2} \dagger$ Habibul Ahsan, ${ }^{1,2} \dagger$ Jill Harkavy Friedman, 1,2 $\dagger$ Dolores Malaspina, ${ }^{1,2} \dagger$ C. Robert Cloninger, ${ }^{2} \neq$ Stephen V. Faraone, ${ }^{2 \ddagger}$ Ming T. Tsuang, ${ }^{2 \ddagger}$ and Charles A. Kaufmann ${ }^{1,2} \dagger^{*}$

${ }^{1}$ Department of Psychiatry, Columbia University College of Physicians and Surgeons, New York, New York ${ }^{2}$ NIMH Genetics Initiative (Columbia University, $\dagger$ Washington University, $\neq$ and Harvard University ${ }^{*}$ )

Anticipation is a genetic phenomenon wherein age of disease onset decreases and/ or severity increases in successive generations. Anticipation has been demonstrated for several neuropsychiatric disorders with expanding trinucleotide repeats recently identified as the underlying molecular mechanism. We report here the results of an analysis of anticipation performed with multiplex families segregating schizophrenia. Thirty-three families were identified through the NIMH Genetics Initiative that met the following criteria: had at least two affected members in successive generations and were not bilineal. Affectation diagnoses included schizophrenia, schizoaffective disorder-depressed, and psychosis NOS. Additional analyses included the Cluster A personality disorders. Three indices of age of onset were used. Disease severity was measured by several different indices. Four sampling schemes as suggested by McInnis et al. were tested, as well as additional analysis using pairs ascertained through the parental generation. Anticipation was demonstrated for age of onset, regardless of the index or sampling scheme used $(P<0.05)$. Anticipation was not supported for disease severity. Analyses that took into account drug use and diminished fecundity did not affect the results. While the data strongly support intergenerational differences in disease onset consistent with anticipation, they must be viewed cautiously given unavoidable biases attending these analyses. Am. J. Med. Genet. 74:275-280, 1997.

() 1997 Wiley-Liss, Inc.

Contract grant sponsor: NIMH Schizophrenia Research Training Award; Contract grant number: 5T32MH19970; Contract grant sponsor: Molecular Genetics of Schizophrenia NIMH; Contract grant number: 2K02MH00682.

*Correspondence to: Charles A. Kaufmann, New York State Psychiatric Institute, Unit 58, 722 W 168th Street, New York, NY 10032.

Received 21 February 1996; Revised 17 October 1996
KEY WORDS: trinucleotide repeats; genetics; age of onset; disease severity

\section{INTRODUCTION}

Anticipation is a genetic phenomenon wherein age of disease onset decreases and disease severity increases in successive generations. This phenomenon was first described in 1910 by Mott who used the term anticipation to describe psychiatric illness. He noted a degeneration in successive generations of "lunatics and imbeciles" [Mott, 1910]. Penrose reintroduced the term in 1948 in relation to myotonic dystrophy. For many years anticipation was thought to be an artifact of ascertainment and other biases such as cohort effects, assortative mating, and increased societal awareness of disease. With the discovery of expanding trinucleotide repeats in the early 1990's [Richards and Sutherland, 1992], however, a convincing molecular mechanism was provided for this phenomenon. The phenomenon is now well described for several neuropsychiatric disorders, including myotonic dystrophy, fragile X syndrome, spinocerebellar atrophy, and Huntington's Disease, among others [see Ross, 1993 for a review]. Anticipation may be preferentially demonstrated in the setting of maternal or paternal transmission; i.e., genomic imprinting [Langlois, 1994]. Recent studies have reported evidence for anticipation in schizophrenia [Asherson et al., 1994; Bassett and Honer, 1994; Aschauer et al., 1995; Gorwood et al., 1995; Thibaut et al., 1995] and bipolar affective disorder [McInnis et al., 1993; Lipp et al., 1995; Serbanescu-Grigoroiu et al., 1995]; preliminary reports of increased trinucleotide repeat size in both disorders suggests that evidence for anticipation may reflect underlying biological phenomena [O'Donovan et al., 1995; Morris et al., 1995; Sirugo et al., 1995; but see Vincent et al., 1995; Jain et al., 1995; Sasaki et al., 1995]. Studies demonstrating anticipation, however, have been plagued by several methodological limitations such as small sample size, non-systematic ascertainment, overly broad definition of affectation, and limited number of measures of disease onset and severity. Here we report the results of an analysis of anticipation performed with 33 multiplex families segregating schizophrenia in which we attempt to address some of these limitations. 


\section{SUBJECTS AND METHODS}

\section{Ascertainment}

Families were identified as part of the NIMH Genetics Initiative. This sample is an evolving resource, which at the time of this analysis comprised 108 multiplex families from three collaborative sites, including Columbia University, Harvard University, and Washington University. Pedigrees are ascertained through consecutive hospital admission of a pair of narrowly affected (i.e., schizophrenia or schizo-affectivedepressed) first degree relatives and are extended according to explicit rules. Further details of ascertainment procedures for these families is described elsewhere [Cloninger, 1994]. A subset of 33 families was identified, which met the following criteria: 1 ) at least one broadly affected (arbitrarily defined as schizophrenia, schizoaffective-depressed, psychosis NOS, or Cluster A personality disorders), interviewed member in two successive generations; 2) no evidence of bilineality, defined as both parents being broadly affected.

\section{Evaluation}

Subjects were interviewed with the Diagnostic Interview for Genetic Studies (DIGS) [Nurnberger et al., 1994]. All available family members were directly interviewed. All diagnoses conformed to DSMIII-R criteria.

\section{Study Sample}

The older generation, designated G1, included 42 affected members, consisting of parents, aunts, and uncles. The younger generation, G2, had 71 affected members, consisting of siblings and first cousins. Breakdown of pairs (G1/G2) by gender was as follows: female $/$ male $=29$, female $/$ female $=20$, male $/$ female $=3$, and male/male $=4$. The preponderance of females in the G1 generation may reflect decreased paternal fecundity, owing to biological or social factors. This distribution prevents an analysis of genomic imprinting, which has been suggested to serve as a criterion in differentiating true from false anticipation [Ridley et al., 1988]. Diagnoses including schizophrenia, schizoaffective-depressed, and psychosis NOS (not associated with an affective disorder) ( $\mathrm{n}=38$ in G1, $\mathrm{n}=52$ in G2) were designated as "core" diagnoses. These diagnoses were chosen as those constituting a range of diagnoses thought to be genetically related to schizophrenia [Kendler et al., 1993]. In addition, the Cluster A personality disorders (schizotypal, paranoid, and schizoid) were included in separate analyses of disease severity ( $\mathrm{n}=42$ in G1 and $\mathrm{n}=71$ in G2) as some or all of these have also been proposed to be genetically related to schizophrenia [Kendler et al., 1993].

\section{Sampling Schemes}

We adopted four major sampling schemes as suggested by McInnis et al. [1993] as one approach to addressing ascertainment bias. These included:

1. Random pairs, in which one randomly affected member in G1 was paired with one randomly se- lected member of G2 $(n=33)$. This scheme included childless members of the older generation, thus addressing the bias that arises when severely ill members of G1 do not produce children.

2. Random transmitting pairs, in which the affected parent was paired with a randomly selected affected child $(n=32)$. This scheme is the most direct test of the anticipation hypothesis, although it does not include childless members of G1.

3. All possible pairs $(n=88)$, which included every affected member of G1 paired with every affected member of G2. This scheme also includes childless members of G1, as well as testing the robustness of the random pairs schemes.

4. All possible transmitting pairs $(n=67)$ in which each affected parent was paired with each of their affected children.

Further analysis was done using only those families in which the proband was ascertained through the parental generation ( $\mathrm{n}=56$ pairs), thus attempting to avoid the potential bias that arises when younger and more severely ill individuals come earlier to medical attention. These individuals were divided into pairs under the above four sampling schemes.

\section{Measures of Anticipation}

Three indices of age of onset were used, which were obtained from the DIGS: age of first psychotic symptoms, age of first psychiatric treatment, and age of first psychiatric hospitalization. Multiple measures to assess disease severity were used including past month GAS, number of psychiatric hospitalizations, polychotomous pattern of disease severity, and global negative and positive symptom severity ratings obtained from SANS [Andreasen, 1983] and the SAPS [Andreasen, 1984], respectively.

\section{Statistical Analyses}

Mean and median age of onset were calculated for all sampling schemes. The difference between the mean and median ages of onset was minimal; therefore median ages are reported. Intergenerational differences of continuous measures were tested using the Wilcoxon signed-rank test, as our sample was demonstrated to show a non-Gaussian distribution.

A series of analyses were undertaken to control for several biases which might interfere with the interpretation of results. 1) The possibility of censored data contributing to intergenerational differences in age of onset of psychotic symptoms was addressed by applying a Kaplan-Meier survival analysis. 2) As described, the generation through which a pedigree was ascertained might again give the appearance of anticipation, as pedigrees ascertained through the younger generation might overrepresent younger and sicker individuals who may be more likely to come to medical attention. This was addressed through separate analysis of intergenerational differences in disease onset in G1and G2-ascertained pedigrees and through an expanded Cox proportional hazards model that took into 
account the generation of ascertainment as a predictor variable. 3) Difference in the age of onset distribution for schizophrenia between the genders is well established [Loranger, 1984]; potential intergenerational differences in the distribution of genders might result, therefore, in intergenerational differences in age of onset, giving the appearance of anticipation. This potential artifact was examined through the aforementioned expanded Cox proportional hazards model that took into account gender, as well as generation, as predictor variables. 4) Because of significant colinearity between the generation and year of birth in this sample, the Cox analysis could not be used to control for birth cohort effect. We did attempt however, to control for presumed cohort related differences in psychotomimetic drug use by conducting analyses with and without the inclusion of those subjects with an onset of psychotomimetic substance abuse (cocaine and phencyclidine) prior to onset of psychotic symptoms. 5) Given the strict requirement for intergenerational correlations in age of onset to ignore ascertainment bias [Hodge, 1995], Pearson correlation coefficients were calculated for all G1 and G2 age of onset measures under each of the sampling schemes.

\section{RESULTS}

\section{Age of Onset}

For all three indices of age of onset, the G2 generation showed a significantly earlier age of onset than the G1 generation, regardless of sampling scheme used, $P$ $<0.05$. Values for all sampling schemes are shown in Table I. Kaplan-Meier survival analysis of onset of psychotic symptoms corroborated a significantly earlier age of onset in G2 (Log Rank $\left.\chi^{2}{ }_{1 \mathrm{df}}=20.96, P<0.001\right)$
(Fig. 1); analyses employing other age of onset measures (first psychiatric treatment and first psychiatric hospitalization) produced similar results. Correlation coefficients and refression coefficients were calculated for all sampling schemes. None of the analyses showed correlation or regression equaled unity.

\section{Disease Severity}

Analyses done with all the measures used for disease severity were not statistically significant under any of the sampling schemes. Table II shows values for all core pairs; the remainder of the data for the other sampling schemes are not shown but were consistent. In addition, G1 and G2 were compared according to the proportion of narrowly versus broadly affected individuals. No differences were seen.

Analyses that only included those pairs ascertained through the parental generation showed similarly significant results (earlier age of onset in G2) as those including the entire sample (data not shown). The comprehensive Cox model that examined intergenerational differences in age of onset, while controlling for both generation of ascertainment and gender also showed a significantly earlier onset of psychotic symptoms in G2 (risk ratio 2.885; 95\% CI 1.666-4.998); analyses employing other age of onset measures produced similar results. Analyses for age of onset that excluded those subjects who had an onset of psychotomimetic substance abuse prior to the onset of psychotic symptoms (37/55 remaining for all core pairs) remained highly significant under all sampling schemes (data not shown). Analyses that included avuncular relationships (random pairs and all possible pairs) showed re-

TABLE I. Age of Onset (G1 vs. G2)

\begin{tabular}{|c|c|c|c|c|c|}
\hline $\begin{array}{l}\text { Sampling } \\
\text { scheme }\end{array}$ & Index & Generation & Number & $\begin{array}{c}\text { Median } \\
\text { (years) }\end{array}$ & $\begin{array}{c}\mathrm{Z} \\
\text { (Wilcoxon) }\end{array}$ \\
\hline \multirow[t]{6}{*}{ All core pairs } & \multirow[t]{2}{*}{ 1st psychosis } & G1 & 55 & 24 & \multirow[t]{2}{*}{$-4.332 *$} \\
\hline & & G2 & 55 & 18 & \\
\hline & \multirow{2}{*}{ 1st treatment } & G1 & 56 & 29 & \multirow{2}{*}{$-4.731^{*}$} \\
\hline & & G2 & 50 & 18 & \\
\hline & \multirow[t]{2}{*}{ 1st hospital } & G1 & 47 & 30 & \multirow[t]{2}{*}{$-3.874^{*}$} \\
\hline & & G2 & 45 & 20 & \\
\hline \multirow[t]{6}{*}{ All core transmitting pairs } & \multirow[t]{2}{*}{ 1st psychosis } & G1 & 38 & 27 & \multirow[t]{2}{*}{$-3.841^{*}$} \\
\hline & & G2 & 39 & 18 & \\
\hline & \multirow[t]{2}{*}{ 1st treatment } & G1 & 40 & 30.5 & \multirow[t]{2}{*}{$-4.584^{*}$} \\
\hline & & G2 & 34 & 17.5 & \\
\hline & \multirow[t]{2}{*}{ 1st hospital } & G1 & 31 & 33 & \multirow[t]{2}{*}{$-3.714^{*}$} \\
\hline & & G2 & 30 & 19 & \\
\hline \multirow[t]{6}{*}{ Random core pairs } & \multirow[t]{2}{*}{ 1st psychosis } & G1 & 22 & 27 & \multirow[t]{2}{*}{$-2.839 * *$} \\
\hline & & G2 & 24 & 19 & \\
\hline & \multirow[t]{2}{*}{ 1st treatment } & G1 & 23 & 29 & \multirow[t]{2}{*}{$-3.321 * *$} \\
\hline & & G2 & 23 & 18 & \\
\hline & \multirow[t]{2}{*}{ 1st hospital } & G1 & 18 & 29.5 & \multirow[t]{2}{*}{$-2.132 * * *$} \\
\hline & & G2 & 19 & 20 & \\
\hline \multirow[t]{6}{*}{ Random core transmitting pairs } & \multirow[t]{2}{*}{ 1st psychosis } & G1 & 21 & 27 & \multirow[t]{2}{*}{$-2.896^{* *}$} \\
\hline & & G2 & 21 & 18 & \\
\hline & \multirow[t]{2}{*}{ 1st treatment } & G1 & 23 & 29 & \multirow[t]{2}{*}{$-3.250 * *$} \\
\hline & & G2 & 21 & 18 & \\
\hline & \multirow{2}{*}{ 1st hospital } & G1 & 18 & 30.5 & \multirow{2}{*}{$-2.480 * * *$} \\
\hline & & G2 & 18 & 20 & \\
\hline
\end{tabular}

$* P<0.000$.

$* * P<0.005$

$* * * P<0.05$ 
TABLE II. Disease Severity (G1 vs. G2)

\begin{tabular}{|c|c|c|c|c|c|}
\hline $\begin{array}{l}\text { Sampling } \\
\text { scheme }\end{array}$ & Index & Generation & Number & Median & Z (Wilcoxon) \\
\hline \multirow[t]{11}{*}{ All core pairs } & $\begin{array}{l}\text { Past month } \\
\text { Gas }\end{array}$ & $\begin{array}{l}\text { G1 } \\
\text { G2 }\end{array}$ & $\begin{array}{l}57 \\
59\end{array}$ & $\begin{array}{l}41 \\
40\end{array}$ & $-1.861^{*}$ \\
\hline & $\begin{array}{l}\text { Number of } \\
\text { hospitalizations }\end{array}$ & $\begin{array}{l}\text { G1 } \\
\text { G2 }\end{array}$ & $\begin{array}{l}45 \\
50\end{array}$ & $\begin{array}{l}3.0 \\
3.0\end{array}$ & $0.169^{*}$ \\
\hline & $\begin{array}{r}\text { Pattern of } \\
\text { severity }\end{array}$ & $\begin{array}{l}\text { G1 } \\
\text { G2 }\end{array}$ & $\begin{array}{l}54 \\
57\end{array}$ & $\begin{array}{l}3.0 \\
3.0\end{array}$ & $-0.325^{*}$ \\
\hline & $\begin{array}{l}\text { Global rating of } \\
\text { alogia }\end{array}$ & $\begin{array}{l}\text { G1 } \\
\text { G2 }\end{array}$ & $\begin{array}{l}57 \\
59\end{array}$ & $\begin{array}{l}2.0 \\
2.0\end{array}$ & $0.097^{*}$ \\
\hline & $\begin{array}{l}\text { Global rating of } \\
\text { avolition }\end{array}$ & $\begin{array}{l}\text { G1 } \\
\text { G2 }\end{array}$ & $\begin{array}{l}56 \\
57\end{array}$ & $\begin{array}{l}3.0 \\
3.0\end{array}$ & $0.494^{*}$ \\
\hline & $\begin{array}{l}\text { Global rating of } \\
\text { anhedonia }\end{array}$ & $\begin{array}{l}\text { G1 } \\
\text { G2 }\end{array}$ & $\begin{array}{l}53 \\
49\end{array}$ & $\begin{array}{l}3.0 \\
3.0\end{array}$ & $-0.434^{*}$ \\
\hline & $\begin{array}{l}\text { Global rating of } \\
\text { attention }\end{array}$ & $\begin{array}{l}\text { G1 } \\
\text { G2 }\end{array}$ & $\begin{array}{l}57 \\
59\end{array}$ & $\begin{array}{l}1.0 \\
2.0\end{array}$ & $1.917^{*}$ \\
\hline & $\begin{array}{l}\text { Global rating of } \\
\text { hallucinations }\end{array}$ & $\begin{array}{l}\text { G1 } \\
\text { G2 }\end{array}$ & $\begin{array}{l}57 \\
59\end{array}$ & $\begin{array}{l}0.0 \\
2.0\end{array}$ & $1.520^{*}$ \\
\hline & $\begin{array}{l}\text { Global rating of } \\
\text { delusions }\end{array}$ & $\begin{array}{l}\text { G1 } \\
\text { G2 }\end{array}$ & $\begin{array}{l}57 \\
59\end{array}$ & $\begin{array}{l}2.0 \\
2.0\end{array}$ & $0.157^{*}$ \\
\hline & $\begin{array}{l}\text { Global rating of } \\
\text { bizarre behavior }\end{array}$ & $\begin{array}{l}\text { G1 } \\
\text { G2 }\end{array}$ & $\begin{array}{l}57 \\
58\end{array}$ & $\begin{array}{l}1.0 \\
0.0\end{array}$ & $-1.720^{*}$ \\
\hline & $\begin{array}{l}\text { Global rating of } \\
\text { formal thought disorder }\end{array}$ & $\begin{array}{l}\text { G1 } \\
\text { G2 }\end{array}$ & $\begin{array}{l}57 \\
59\end{array}$ & $\begin{array}{l}2.0 \\
2.0\end{array}$ & $-1.720^{*}$ \\
\hline
\end{tabular}

$* P=$ Not significant.

sults consistent with analyses using transmitting pairs.

\section{DISCUSSION}

Our results demonstrate intergenerational differences in age of onset in familial schizophrenia and are consistent with other findings from previous studies [Bassett and Honer, 1994; Asherson et al., 1994]. Earlier studies, however, were limited in sample size, in being based on samples that were not systematically ascertained, and in relying on individual and/or arbitrary measures of disease onset and severity. While the size of the current sample is still modest, this study has

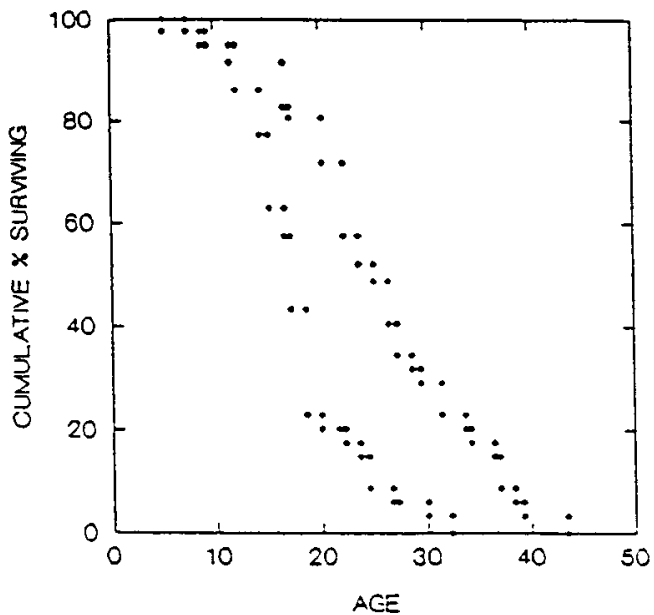

Fig. 1. Kaplan-Meier survival analysis of onset of psychotic symptoms. Open, G1; closed, G2. attempted to address the other limitations of earlier studies: 1. families were systematically ascertained thus allowing for replication (it should be noted, however, that such systematic ascertainment may not circumvent ascertainment bias, as discussed below). 2 . Three different measures of age of onset were used, as were several measures of disease severity. 3. Several different sampling schemes are tested. 4. Both narrow and broad diagnostic categories were tested.

While our results suggest the occurrence of anticipation in age of onset, several confounding variables and biases need to be considered. Although Asherson et al. [1994], finding no correlation between age of onset in their G1 and G2 generations, attributed their results to regression to the mean rather than true anticipation, other authors [Hodge and Wickramaratne, 1995: Petronis, 1994] have argued that correlation and anticipation are distinct phenomena and that it is possible to have anticipation without correlation. Nonetheless, in the absence of correlation one still has to consider ascertainment biases influencing outcomes [Hodge and Wickramaratne, 1995]. Hodge and Wickramaratne [1995] further state that ascertainment bias can be circumvented if both the regression coefficient beta and the correlation coefficient rho equal unity, but concede that this is unlikely to occur in actual practice and may be of more theoretical rather than practical interest. As none of our analyses demonstrated the above criteria, ascertainment bias must still be considered a potential confound of the present study. Ascertainment biases that may produce intergenerational differences in age of onset include the following: 1) offspring with later ages of onset are less likely to be designated as affected, 
2) earlier and more severely affected individuals are less likely to reproduce, and 3) earlier cases and more severe cases are more likely to come to medical attention [Ridley, 1988].

Although ascertainment bias may be ultimately inescapable in this sample, we attempted to minimize problems attributable to case selection by excluding families with evidence of bilineality (as assortative mating is common in psychiatric disorders and the convergence of two parental genetic contributions could simulate anticipation), by utilizing three different measures of age of onset and four different sampling schemes (thereby attesting to the robustness of any finding), by examining intergenerational pairs by gender and including gender in an expanded hazards analysis, thus lessening the impact of known gender differences in the age of onset of schizophrenia [Loranger, 1984]. Moreover, we attempted to minimize problems attributable to diminished fecundity (a known characteristic of schizophrenia [ErlenmeyerKimling and Paradowski, 1966] with more severe and earlier onset cases less likely to reproduce [Haverkamp et al., 1982]) by 1) carrying out analyses using only those pairs in which the ascertained proband was in the G1 generation and 2) including avuncular relationships in the analyses consisting of all pairs and random pairs.

In addition to potential difficulties in case selection, other potential confounds include cohort effects, recall bias, and sensitization to illness. Differences in age of onset or disease severity in successive birth cohorts, as has been described for affective disorders [Gershon et al., 1987] and for schizophrenia [GAP, 1992] could give the appearance of differences in these characteristics in successive generations. Cox proportional hazard analyses examining birth cohort and generations independent predictor variables are ideally suited to disentangle these effects. Unfortunately, the colinearity of these variables in this sample rendered this analysis uninterpretable. Nonetheless, an attempt was made to eliminate possible bias due to secular trends in substance abuse by excluding those pairs in which substance use occurred prior to the onset of psychotic symptoms. Excluding such pairs from the analysis did not significantly change the results.

The question arises as to whether members of G1 reported a later age of onset because of recall bias, i.e., biased reporting of later ages of onset owing to selective forgetting of earlier episodes [Warshaw et al., 1991]. Degradation of information over time represents an important confound. We attempted to address this issue by utilizing three different measures of age-of-onset. Another related potential confound arises because the selected families all contained affected individuals in the older generation. Thus, it is likely that the older generation was cognizant of the first symptoms of schizophrenia causing them to seek psychiatric help and/or hospitalization for the younger generation at an earlier age. This sensitization in the older generation could result in earlier treatment, including hospitalization, in the younger generation. Again, this confound was addressed by utilizing three different measures of age of onset. Although we could not demonstrate inter- generational differences in disease severity, this may reflect a Type II error owing to inadequate measures of severity. The GAS, SANS, and SAPS score reflect current functioning and thus are not a good measure of lifetime severity. Likewise, many of our disease severity measures have limited variability, reducing their usefulness. Still unresolved is what would constitute a reliable measure of disease severity.

Although repeatedly demonstrated in several neuropsychiatric disorders, including schizophrenia, the interpretation of intergenerational differences in disease onset and severity continues to be complex. This is especially so in complex disorders that do not follow Mendelian patterns of inheritance. The presence of anticipation, suggesting trinucleotide repeat expansion, in even a subset of families segregating schizophrenia might shed light on this complex pattern of inheritance, which includes variable penetrance and expressivity. Preliminary evidence for repeat expansion in schizophrenia using the RED assay [O'Donovan, 1995; Morris, 1995; Sirugo et al., 1995], while not consistently observed [Vincent et al., 1995] lends credence to a biological basis for the phenomenon of anticipation. Clearly, pairwise comparison of repeat length in pedigrees, such as those described here, showing intergenerational differences in disease expression, would help to reconcile these epidemiologic and molecular genetic findings. Screening brain-derived cDNA libraries for expanding trinucleotide repeats provides a complementary approach to defining those genes that might contribute to anticipation [Ross et al., 1993]. The data described herein suggest that these molecular approaches should proceed with caution, especially given the possible biases we have identified. Nonetheless, the possibility that these differences reflect biology, and not bias, holds great promise for our understanding of schizophrenia.

\section{ACKNOWLEDGMENTS}

This work was supported by NIMH Schizophrenia Research Training Award 5T32MH19970 (JEJ), and Molecular Genetics of Schizophrenia NIMH 2K02MH00682 (CAK). The authors wish to thank Dr. Sue Hodge, Dr. Mel McInnis, and Dr. Anne Bassett for their thoughtful comments and review of this work. This paper is based in part on presentations at the American Psychiatric Association's Annual Meeting, Miami, May 1995 and the World Congress on Psychiatric Genetics, Cardiff, Wales, August, 1995.

\section{REFERENCES}

Andreasen NC (1983): "The Scale for the Assessment of Negative Symptoms (SANS)." Iowa City: The University of Iowa.

Andreasen NC (1984): "The Scale for the Assessment of Positive Symptoms (SAPS)." Iowa City: The University of Iowa.

Aschauer HN, Heiden AM, Willinger U, Meszaros K, Miller-Reiter E, Stompe T, Lenzinger E, Resinger E, Scharfetter J, Strobl R, Kasper S (1995): Study of anticipation in schizophrenia. Psychiatric Genet 5:S7.

Asherson P, Walsh C, Williams J, Sargeant M, Taylor C, Clements A, Gill M, Owen M, McGuffin P (1994): Imprinting and anticipation: Are they relevant to genetic studies of schizophrenia? Br J Psychiatry 164:619624 . 
Bassett AS, Honer WG (1994): Evidence for anticipation in schizophrenia. Am J Hum Genet 54:864-870.

Cloninger CR (1994): Turning point in the design of linkage studies. Am J Med Genet 54:83-92.

Erlenmeyer-Kimling LE, Paradowski W (1966): Selection and schizophrenia. Am Naturalist 100:651-665

Gershon ES, Hamovit JH, Guroff JJ, Nurnberger JI (1987): Birth-cohort changes in manic and depressive disorders in relatives of bipolar and schizoaffective patients. Arch Gen Psychiatry 44:314-319.

Gorwood P, Leboyer M, Fallissard B, Jay M, Rouillon F, Ades J, Feingold $J$ (1995): Anticipation in schizophrenia: New light on a controversial problem. Psychiatric Genet 5:S7.

Group for the Advancement of Psychiatry (1992): The postinstitutional generation: Cohort effects and long-term outcome in schizophrenia. In "Beyond Symptom Suppression: Improving Long-Term Outcomes in Schizophrenia." Washington, D.C.: American Psychiatric Press.

Haverkamp F, Propping P, Hilger T (1982): Is there an increase of reproductive rates in schizophrenics? ARCH Psychiatr Nervenkr 232:439450.

Hodge SE, Wickramaratne P (1995): Statistical pitfalls in detecting ageof-onset anticipation: The role of correlation in studying anticipation and detecting ascertainment bias. Psychiatric Genet 5:43-47.

Jain S, Leggo J, DeLisi LE, Crow TJ, Margolis RL, Shi-Hua Li, Goodburn S, Walsh C, Paykel ES, Ferguson MA, Ross CA, Rubinsztein (1995): Analysis of thirteen trinucleotide repeat loci as candidate genes for schizophrenia and bipolar affective disorder. Psychiatric Genet 5:58.

Kendler KS, McGuire M, Gruenberg AM, O'Hare A, Spellman M, Walsh D (1993): The Roscommon family study. I. Methods, diagnosis of probands, and risk of schizophrenia in relatives. Arch Gen Psych 50:527540 .

Kendler KS, McGuire M, Gruenberg AM, O'Hare A, Spellman W, Walsh D (1993): The Roscommon family study. III. Schizophrenia-related personality disorders in relatives. Arch Gen Psych Vol 50:781-788.

Langlois S (1994): Genomic imprinting: A new mechanism for disease. Pediatr Pathol 4:161-165.

Lipp O, Souery D, Mahieu B, DeBruyn A, Van Broeckhoven C, Mendlewicz $J$ (1995): Anticipation in affective disorders. Psychiatric Genet 5:S8.

Loranger AW (1984): Sex difference in age of onset of schizophrenia. Arch Gen Psychiatry 41:157-161.

McInnis MG, McMahon FJ, Chase GA, Simpson SG, Ross CA, DePaulo JR (1993): Anticipation in bipolar affective disorder. Am J Hum Genet 53:385-390.

Morris AG, Gaitonde E, McKenna PJ, Mollon JD, Hunt DM (1995): Asso- ciation study of CAG expansions with schizophrenia. Schizophr Res 15:41.

Mott FW (1910): Hereditary aspects of nervous and mental diseases. $\mathrm{Br}$ Med J 2:1013-1020.

Nurnberger JI, Blehar MC, Kaufmann CA, York-Cooler C, Simpson SG, Harkavy Friedman J, Severe JB, Malaspina D, Reich T, collaborators from the NIMH Genetics Initiative (1994): Diagnostic interview for genetic studies: Rationale, unique features, and training. Arch Gen Psychiatry 51:849-859.

O'Donovan MC, Guy C, Craddock N, Murphy KC, Cardno AG, Jones LA, Owen MJ, McGuffin P (1995): Expanded CAG repeats in schizophrenia and bipolar disorder. Nature Genet 10:380-381.

Penrose LS (1948): The problem of anticipation in pedigrees of dystrophia myotonica. Ann Eugen 125-132.

Petronis A, Sherrington R, Kennedy JL (1994): Regression to the mean does not exclude anticipation and unstable DNA disease. Am J Hum Genet 55:589-590.

Richards RI, Sutherland GR (1992): Dynamic mutations: A new class of mutations causing human disease. Cell 70:709-712.

Ridley RM, Frith CD, Crow TJ, Conneally PM (1988): Anticipation in Huntington's disease is inherited through the male line but may originate in the female. J Med Genet 25:589-595.

Ross CA, McInnis MG, Margolis RI, Li S-H (1993): Genes with triplet repeats: Candidate mediators of neuropsychiatric disorders. Trends Neurosci 16:254-260

Sasaki T, Billett E, Petronis A, Ying D, Parsons T, Macciardi FM, Meltzer HY, Lieberman J, Ross CA, McInnis MG, Li S-H, Kennedy JL (1995) Psychosis and genes with trinucleotide repeat polymorphism. Psychiatric Genet 5:59.

Serbanescu-Grigoroiu M, Wickramaratne P, Hodge SE (1995): Age of onse and current age in the estimation of genetic anticipation in bipolar I illness. Psychiatric Genet 5:S10.

Sirugo G, Haaf T, Parnas J, Matthysse S, Levy D, Holtzman P, Kidd K (1995): A (CTG)n expansion detected by RED in a schizophrenia kindred maps to $18 \mathrm{q} 21$ by FISH with a CTG/CAG polymer. Am J Hum Genet 57:A36.

Thibaut F, Martinez M, Campion D, Jay M, Petit M (1995): Anticipation in schizophrenia. Psychiatric Genet 5:S10.

Vincent JB, Petronis A, Klempan T, Gottesman I, Torrey EF, Kennedy JL (1995): Repeat expansion detection in manic depression and schizophrenia. Am J Hum Genet 57:A335.

Warshaw MG, Klerman GJ, Lavori PW (1991): Are secular trends in major depression an artifact of recall? J Psychiatr Res 25:141-151. 